\title{
1 Analysis of surface segregation of bottlebrush 2 polymer additives in thin film blends with 3 attractive intermolecular interactions
}

4

5
Kazuma Miyag, ${ }^{a, b}$ Hao Mei, ${ }^{b}$ Travis S. Laws, ${ }^{c}$ Tanguy Terlier, ${ }^{d}$ Gila E. Stein, ${ }^{* b}$ Rafael Verduzco ${ }^{*}, e$

${ }^{a}$ Department of Applied Life Science, Faculty of Applied Biological Sciences, Gifu University, Japan, Gifu 501-1193

${ }^{b}$ Department of Chemical and Biomolecular Engineering, Rice University, Houston, TX 77005

${ }^{\mathrm{c}}$ Department of Chemical and Biomolecular Engineering, University of Tennessee, Knoxville, TN 37996 dSIMS Lab, Shared Equipment Authority, Rice University, Houston, TX 77005 ${ }^{\mathrm{e} D e p a r t m e n t ~ o f ~ M a t e r i a l s ~ S c i e n c e ~ a n d ~ N a n o E n g i n e e r i n g, ~ R i c e ~ U n i v e r s i t y, ~ H o u s t o n, ~ T X ~} 77005$ Email: rafaelv@rice.edu, gestein@utk.edu 


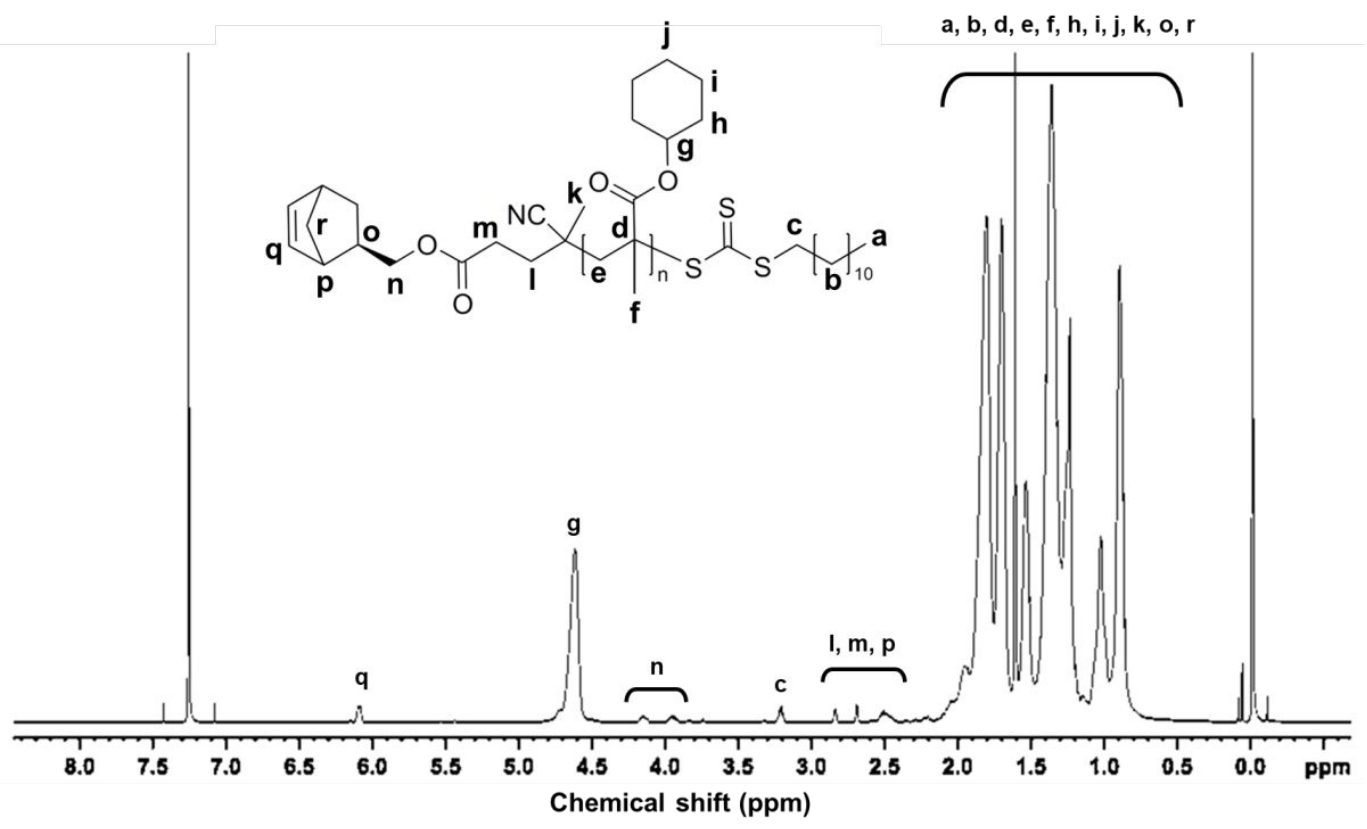

Figure S1. ${ }^{1} \mathrm{H}$ NMR spectra of NBPCHMA macromonomer in $\mathrm{CDCl}_{3}$. 


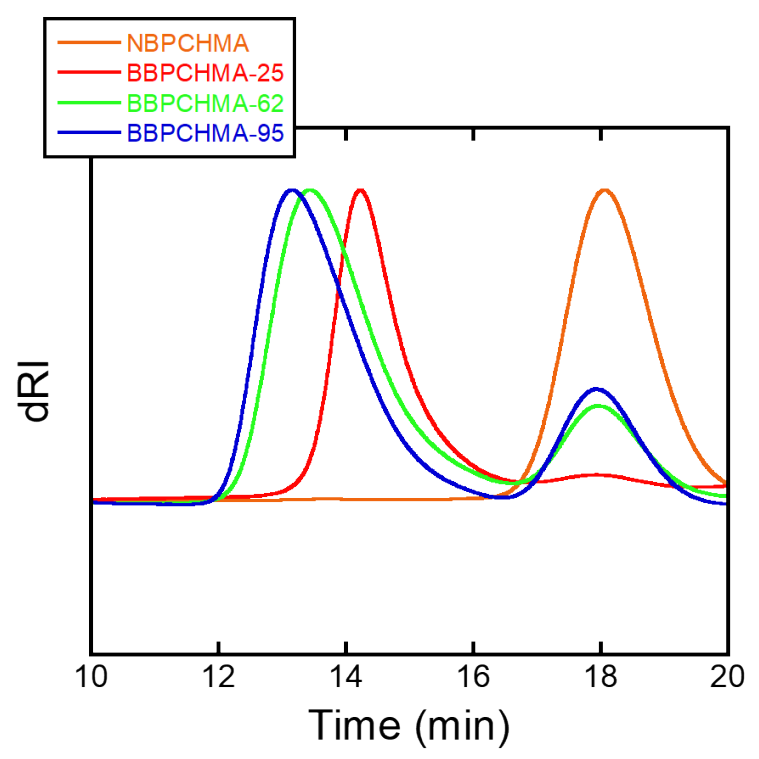

Figure 2. GPC traces of NBPCHMA and BBPCHMAs. The purity of the bottlebrush polymer is at least $85 \mathrm{wt} \%$. 


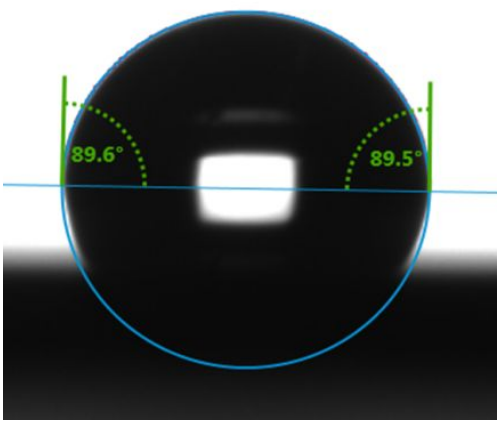

Figure S3. Water contact angle of the PS-coated substrate. 
Table S1. Thickness data of the series of BBPCHMA/PS blends (a) as-cast and (b) annealed at $41 \quad 150{ }^{\circ} \mathrm{C}$ for 2 days.

42

43

\begin{tabular}{|c|c|c|c|c|c|}
\hline \multirow[t]{2}{*}{ (a) } & & \multicolumn{4}{|c|}{$N_{\mathrm{m}} / N_{\mathrm{sc}}$} \\
\hline & & 0.68 & 3.7 & 13 & 26 \\
\hline \multirow{3}{*}{$\frac{z^{0}}{z^{\infty}}$} & 0.57 & $141 \mathrm{~nm}$ & $113 \mathrm{~nm}$ & $100 \mathrm{~nm}$ & $115 \mathrm{~nm}$ \\
\hline & 1.4 & $133 \mathrm{~nm}$ & $123 \mathrm{~nm}$ & $161 \mathrm{~nm}$ & $109 \mathrm{~nm}$ \\
\hline & 2.2 & $193 \mathrm{~nm}$ & $118 \mathrm{~nm}$ & $121 \mathrm{~nm}$ & $118 \mathrm{~nm}$ \\
\hline
\end{tabular}

\begin{tabular}{|c|c|c|c|c|c|}
\hline \multirow[t]{2}{*}{ (b) } & & \multicolumn{4}{|c|}{$N_{\mathrm{m}} / N_{\mathrm{sc}}$} \\
\hline & & 0.68 & 3.7 & 13 & 26 \\
\hline \multirow{3}{*}{$\frac{z^{n}}{z^{\infty}}$} & 0.57 & $150 \mathrm{~nm}$ & $144 \mathrm{~nm}$ & $98 \mathrm{~nm}$ & $107 \mathrm{~nm}$ \\
\hline & 1.4 & $123 \mathrm{~nm}$ & $127 \mathrm{~nm}$ & $131 \mathrm{~nm}$ & $102 \mathrm{~nm}$ \\
\hline & 2.2 & $180 \mathrm{~nm}$ & $106 \mathrm{~nm}$ & $123 \mathrm{~nm}$ & $113 \mathrm{~nm}$ \\
\hline
\end{tabular}

44

45

46 
47 48

49 50

51 52

53

54

5. Schematic of ToF-SIMS wedge crater analysis

Angle View

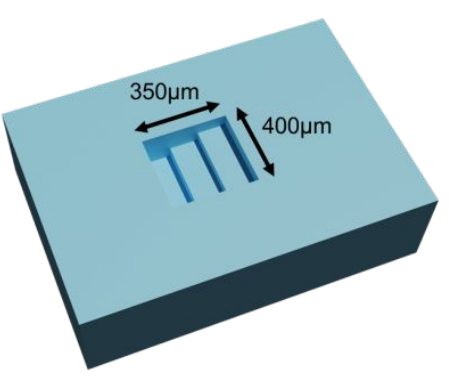

Side view

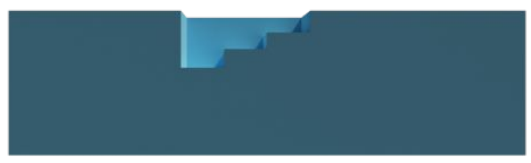

Figure S4. Schematic illustration of angle view and side view of wedge crater for BBPCHMA25/PS120 blend. 


\section{Calibration and normalization of secondary ion-intensities from ToF-SIMS} $\underline{\text { measurements }}$

We calibrated and normalized the secondary ion intensity signals from ToF-SIMS measurements through analysis of a series of blends of NBPCHMA in PS3. Low molecular weight polymer blends were chosen to ensure full miscibility, and no evidence of interfacial segregation was observed in the blends. For each blend, we determined the average of the intensity ratio of $\mathrm{C}_{6} \mathrm{H}_{11}{ }^{+}$ions $\left(I_{\mathrm{C} 6 \mathrm{H} 11}\right)$ to that of $\mathrm{C}_{7} \mathrm{H}_{7}{ }^{+}\left(I_{\mathrm{C} 7 \mathrm{H} 7}\right)$ through a ToF-SIMS depth profiling measurement. Since PS also contribute to $\mathrm{C}_{6} \mathrm{H}_{11}{ }^{+}$ions, $I_{\mathrm{C} 6 \mathrm{H} 11} / I_{\mathrm{C} 7 \mathrm{H} 7}$ was not zero even for a pure PS3 film. Background correction was thus made by subtracting $I_{\mathrm{C} 6 \mathrm{H} 11} / I_{\mathrm{C} 7 \mathrm{H} 7}$ value for pure PS3 film from that of each blend film. These values are provided in Table S2.

Table S2. Secondary ion-intensity ratios $\left(I_{\mathrm{C} 6 \mathrm{H} 11} / I_{\mathrm{C} 7 \mathrm{H} 7}\right)$ for NBPCHMA/PS blends as a function of NBPCHMA composition.

\begin{tabular}{cccc}
\hline $\begin{array}{c}\text { NBPCHMA } \\
\mathrm{wt} \%\end{array}$ & $\begin{array}{c}\text { PCHMA/PS } \\
\text { mass ratio }\end{array}$ & $I_{\mathrm{C} 6 \mathrm{H} 11} / I_{\mathrm{C} 7 \mathrm{H} 7}$ & $\begin{array}{c}\text { Background-corrected } \\
I_{\mathrm{C} 6 \mathrm{H} 11} / I_{\mathrm{C} 7 \mathrm{H} 7}\end{array}$ \\
\hline 0 & 0 & 0.001540 & 0 \\
2.51 & 0.0257 & 0.003701 & 0.002161 \\
5.01 & 0.0527 & 0.008147 & 0.006607 \\
30.3 & 0.435 & 0.05438 & 0.05284 \\
50.1 & 1.004 & 0.1119 & 0.1104 \\
66.7 & 2.003 & 0.1993 & 0.1978 \\
87.3 & 6.874 & 0.6850 & 0.6835 \\
\hline
\end{tabular}

a the secondary ion intensity ratios represent averaged values through the depth of each blend film.

Figure S5 shows plots of background-corrected $I_{\mathrm{C} 6 \mathrm{H} 11} / I_{\mathrm{C} 7 \mathrm{H} 7}$ values as a function of PCHMA/PS ratio for the series of NBPCHMA/PS blends. The mass ratio and the ion intensity ratio exhibited the linear relationship. The mass fractions of PCHMA for the BBPCHMA/PS and linear PCHMA/PS blends shown in main text were calculated from their $I_{\mathrm{C} 6 \mathrm{H} 11} / I_{\mathrm{C} 7 \mathrm{H} 7}$ values using this calibration line. 


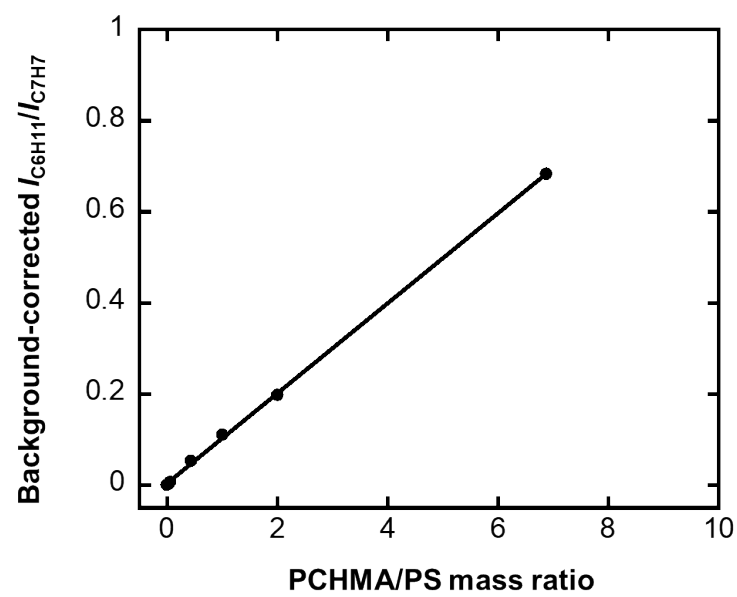

Figure S5. Background-corrected secondary ion-intensity ratio $\left(I_{\mathrm{C} 6 \mathrm{H} 11} / I_{\mathrm{C} 7 \mathrm{H} 7}\right)$ as a function of PCHMA/PS mass ratio for the series of NBPCHMA/PS blends.

To normalize the mass fraction of PCHMA determined from the secondary ion intensity ratios, the integrated value of the PCHMA mass fraction through film thickness is set to 0.1 which is the PCHMA content in each blend film.

86 
89
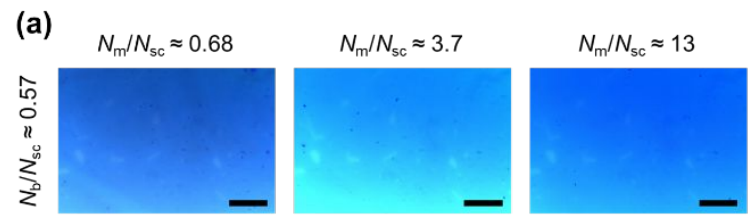

$N_{\mathrm{m}} / N_{\mathrm{sc}} \approx 26$
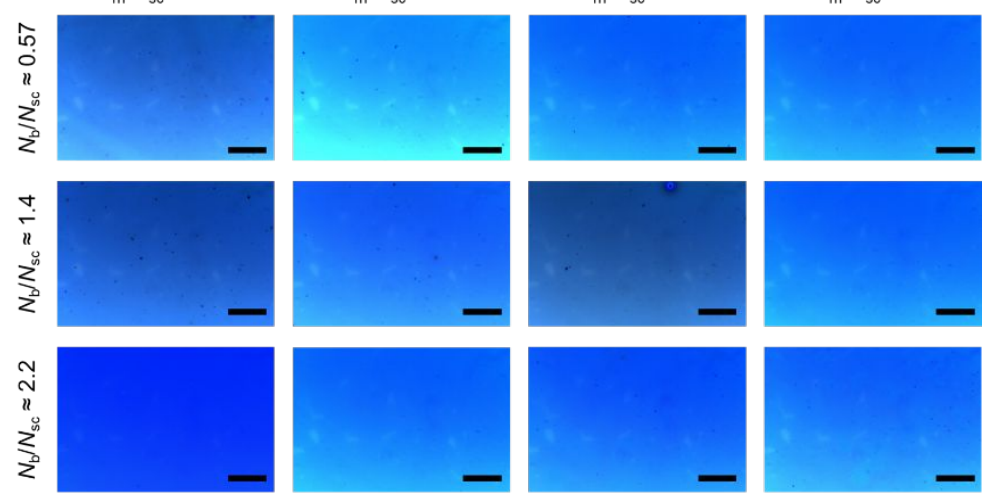

90
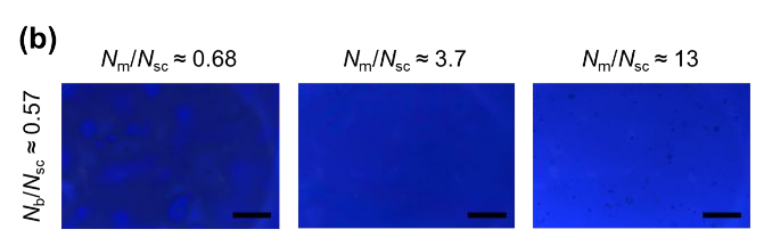

$N_{\mathrm{m}} / N_{\mathrm{sc}} \approx 26$

91
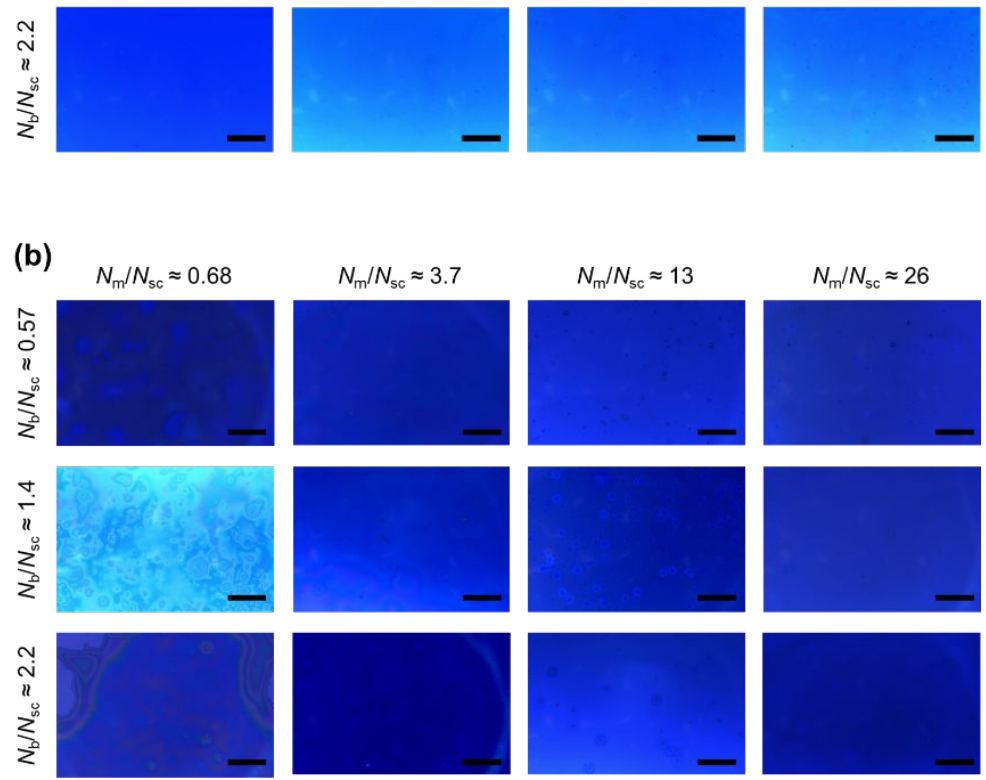

93

Figure S6. Optical micrographs of the series of BBPCHMA/PS blends (a) as-cast and (b) annealed at $150{ }^{\circ} \mathrm{C}$ for 2 days. Scale bar represents $50 \mu \mathrm{m}$. 
98

(a)

$N_{\mathrm{b}} / N_{\mathrm{sc}} \approx 0.57$

$N_{\mathrm{b}} / N_{\mathrm{sc}} \approx 1.4$

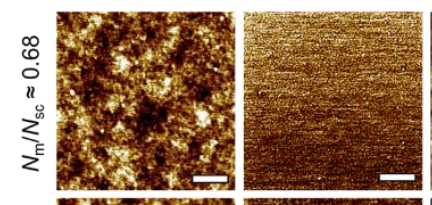

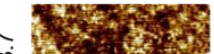

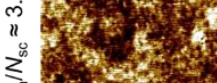

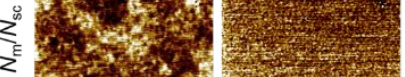

응

${ }_{n}^{\infty}$

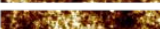

Hans
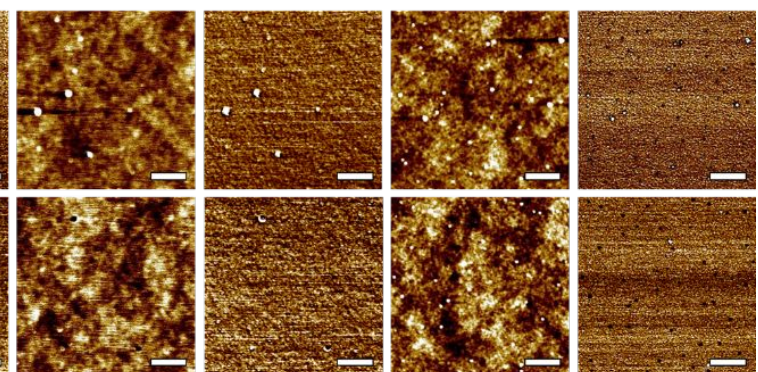

99
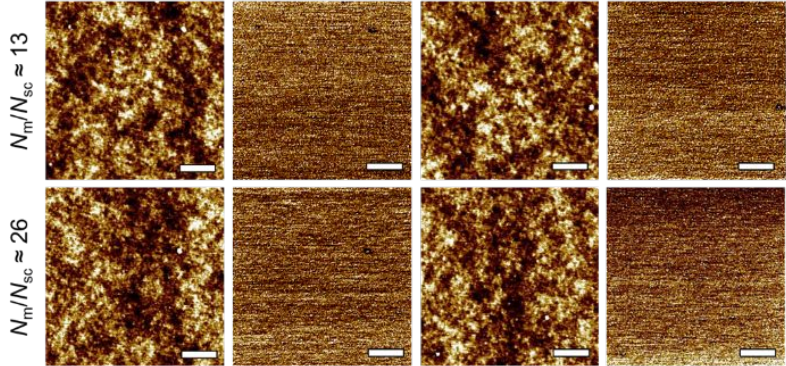

Height

Phase

Height

Phase

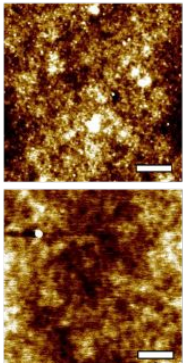

Height

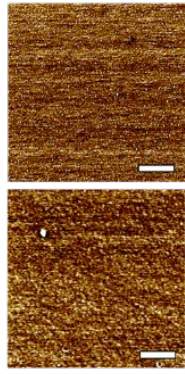

Phase

100

(b)

$N_{\mathrm{b}} / N_{\mathrm{sc}} \approx 1.4$

$N_{\mathrm{b}} / N_{\mathrm{sc}} \approx 2.2$
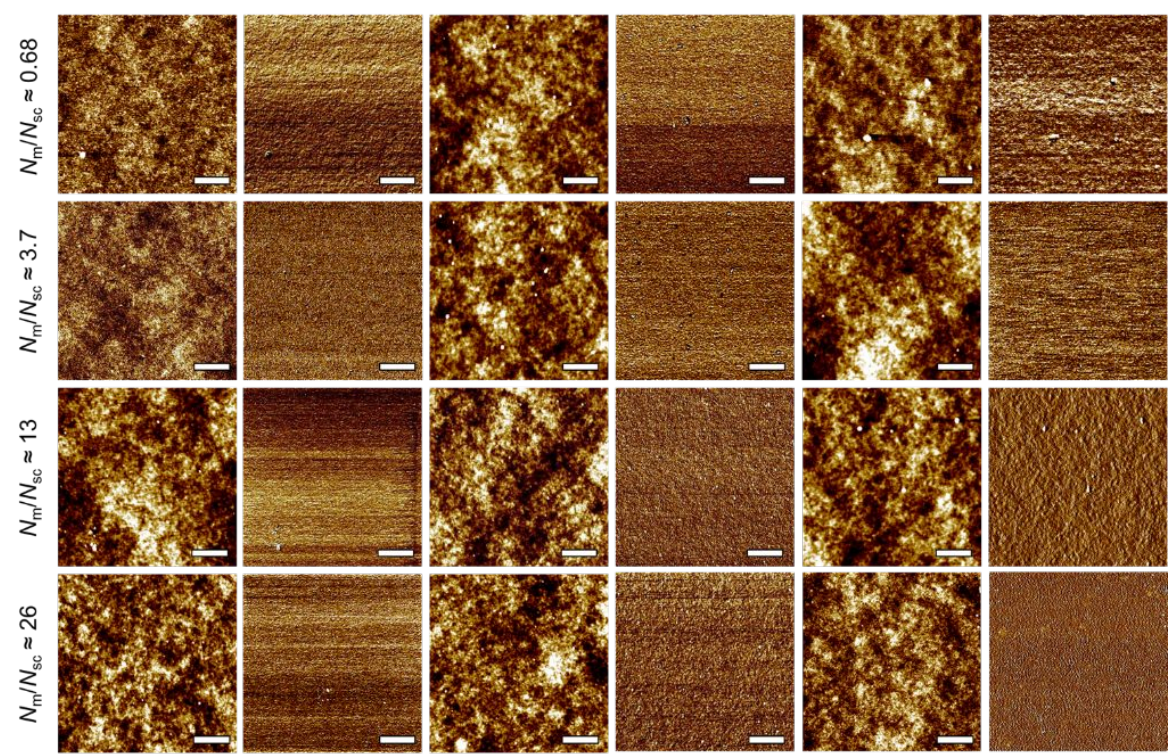

Height

Phase

Height

Phase

Figure S7. AFM height and phase images of the series of BBPCHMA/PS blends (a) as-cast and (b) annealed at $150{ }^{\circ} \mathrm{C}$ for 2 days. Scale bar represents $1 \mu \mathrm{m}$. 

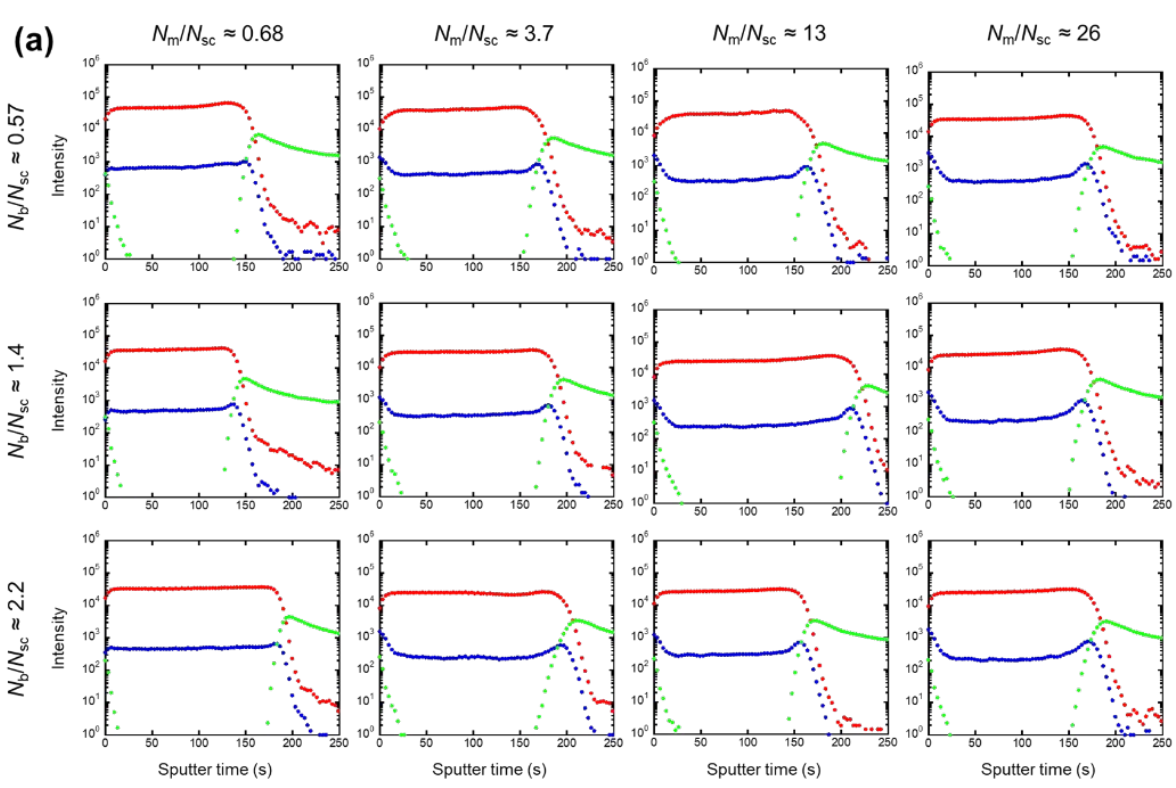

109
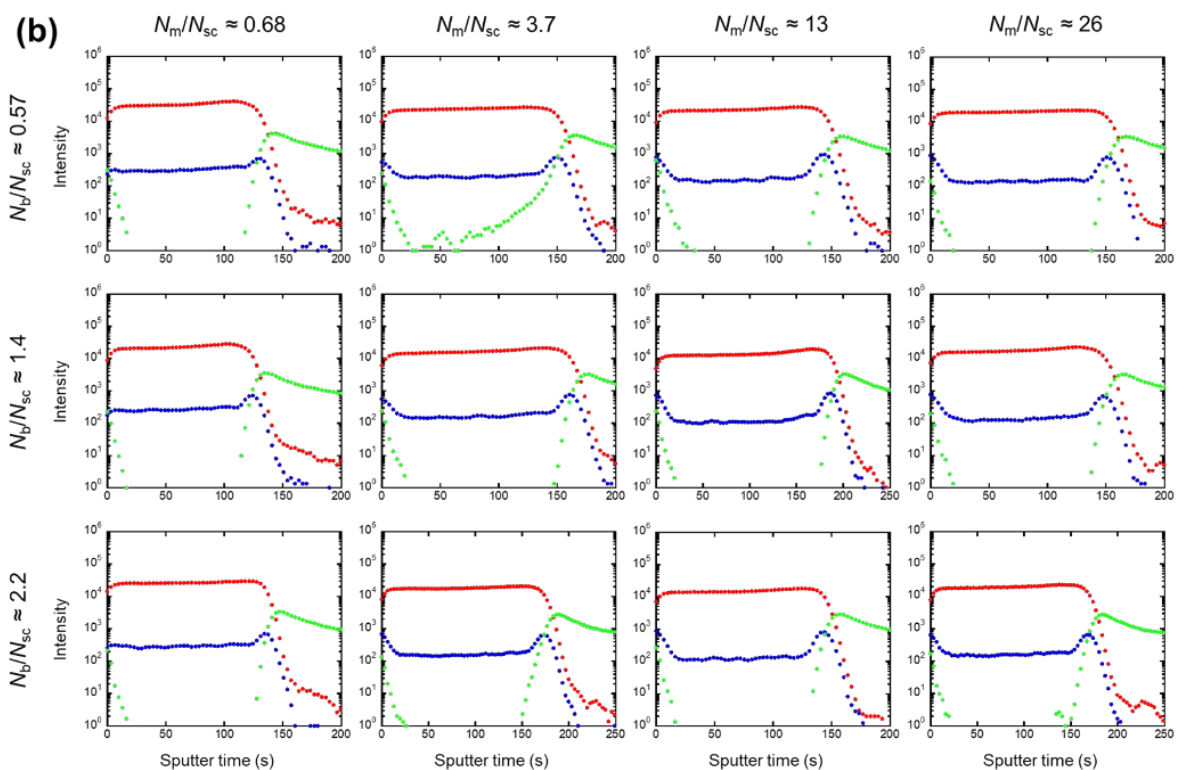

Figure S8. Uncalibrated secondary ion-intensities measured during ToF-SIMS depth profiling of the series of BBPCHMA/PS blends (a) as-cast and (b) annealed at $150{ }^{\circ} \mathrm{C}$ for 2 days. $\mathrm{C}_{6} \mathrm{H}_{11}{ }^{+}$ (from PCHMA), $\mathrm{C}_{7} \mathrm{H}_{7}^{+}$(from PS), and $\mathrm{Si}^{+}$(from substrate) secondary ions are indicated in blue, red, and green, respectively. 

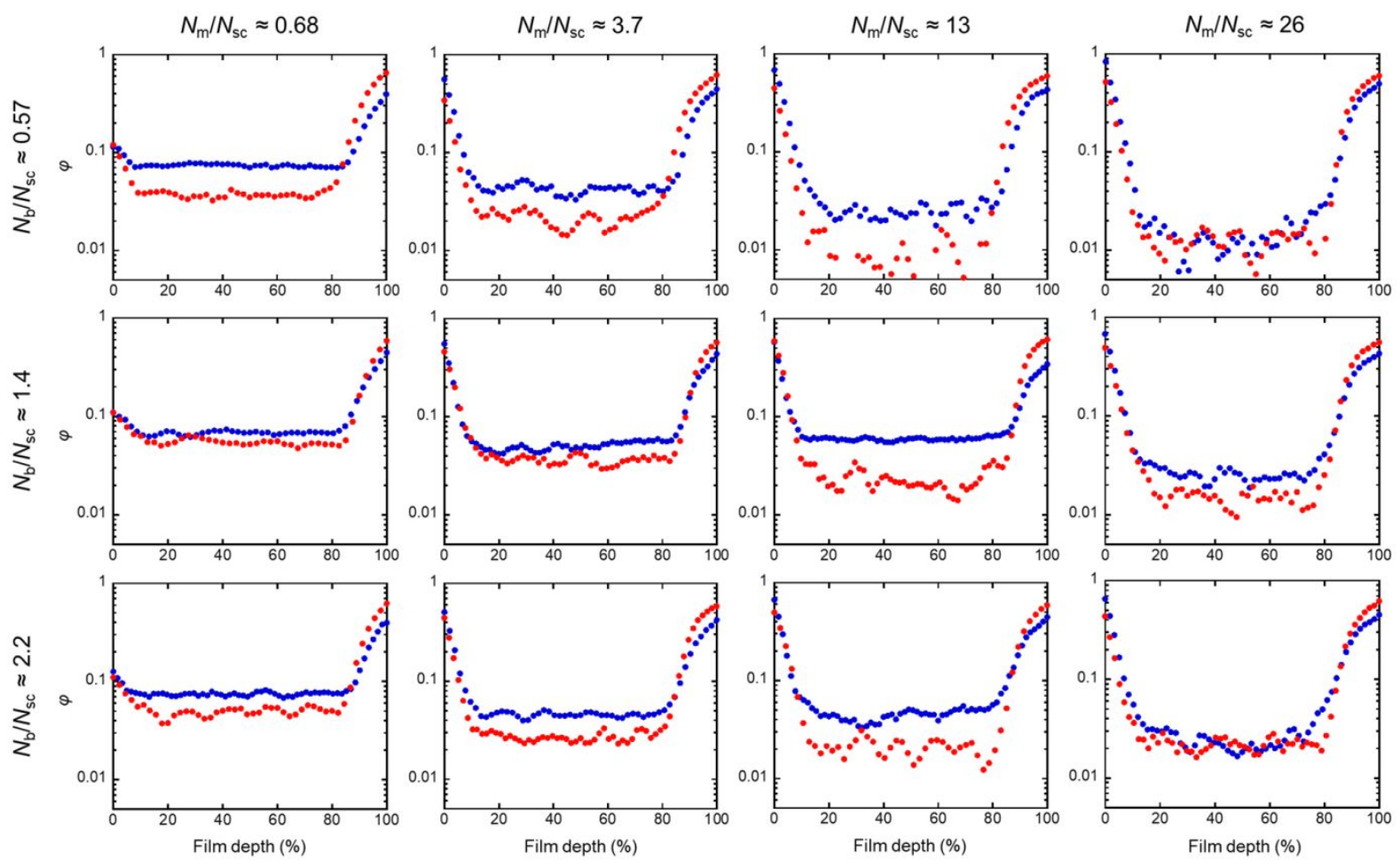

Figure S9. Mass fraction $\varphi$ of BBPCHMA as a function of film depth in BBPCHMA/PS ascast (blue) and annealed (red) blend films. The polymer-air interface and substrate interface of the film are at 0 and $100 \%$ film depth, respectively.
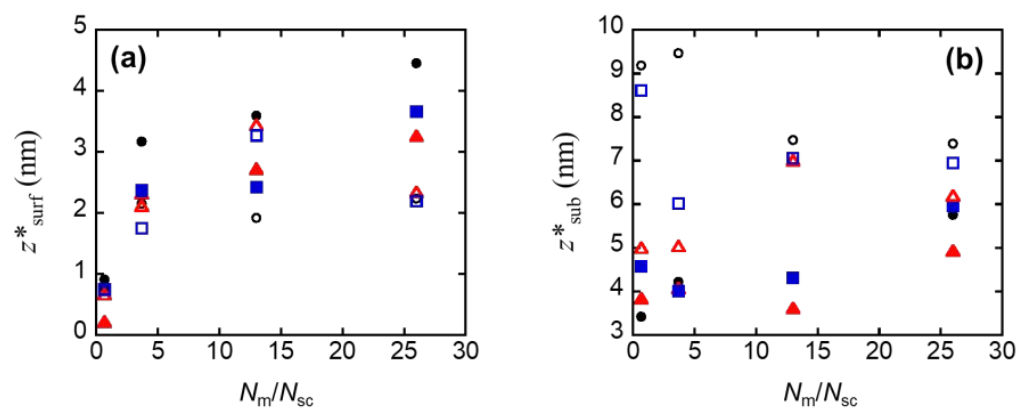

Figure S10. (a) Surface excess $z_{\text {surf }}$ and (b) substrate excess $z{ }_{\text {sub }}$ for BBPCHMA/PS as-cast (closed symbol) and annealed (open symbol) blends as a function of $N_{m} / N_{s c}$. 
(a) $\quad N_{\mathrm{m}} / N_{\mathrm{sc}} \approx 0.68$

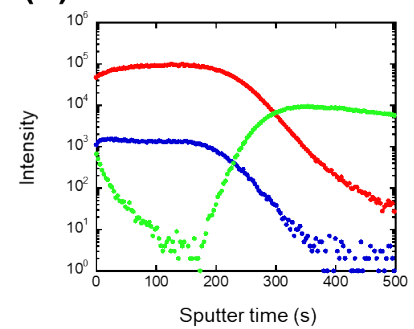

(b)

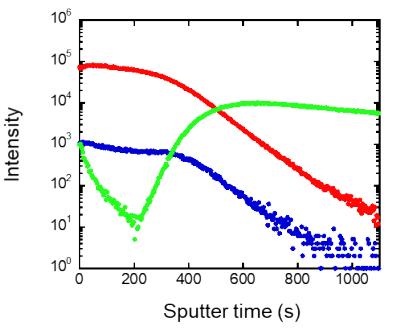

$N_{\mathrm{m}} / N_{\mathrm{sc}} \approx 3.7$
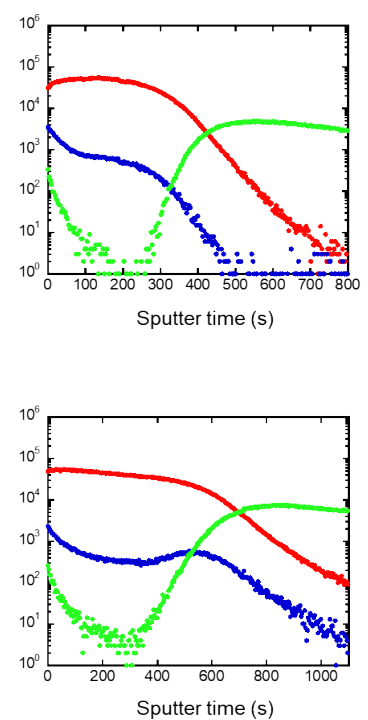

$N_{\mathrm{m}} / N_{\mathrm{sc}} \approx 13$

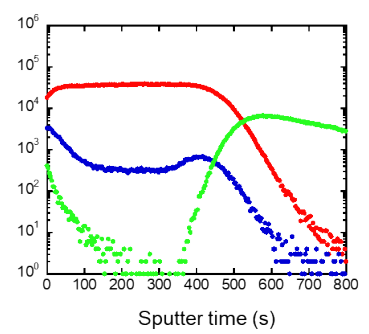

Sputter time (s)

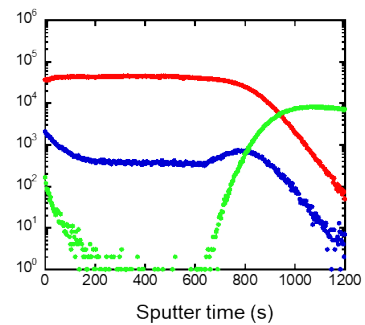

$N_{\mathrm{m}} / N_{\mathrm{sc}} \approx 26$
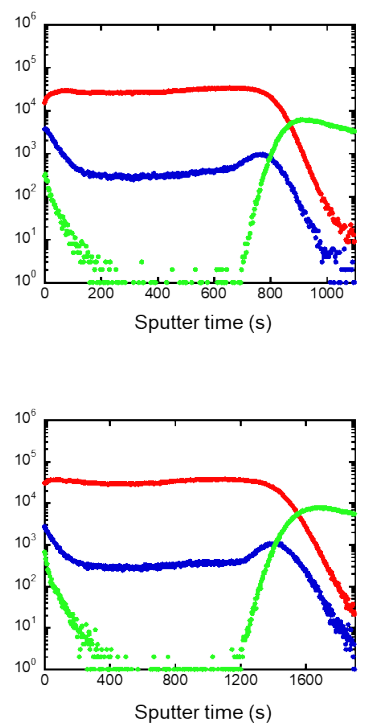

Figure S11. Uncalibrated secondary ion-intensities measured during ToF-SIMS depth profiling of (a) as-cast and (b) annealed BBPCHMA-62/PS blends on the PS-coated substrate. $\mathrm{C}_{6} \mathrm{H}_{11}{ }^{+}$ (from PCHMA), $\mathrm{C}_{7} \mathrm{H}_{7}^{+}$(from PS), and $\mathrm{Si}^{+}$(from substrate) secondary ions are indicated in blue, red, and green, respectively.
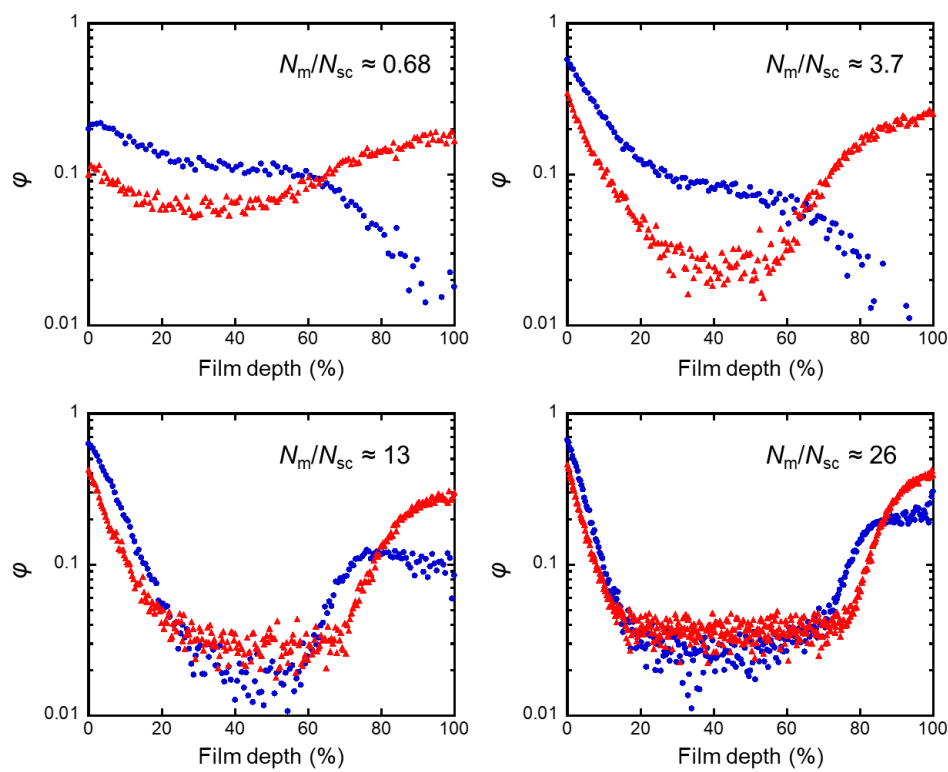

Figure 12. Mass fraction $\varphi$ of BBPCHMA as a function of film depth in BBPCHMA-62/PS ascast (blue) and annealed (red) blend films. The polymer-air interface and substrate interface are at 0 and $100 \%$ film depth, respectively. 


\section{Supporting data for linear PCHMA/PS blends}

142
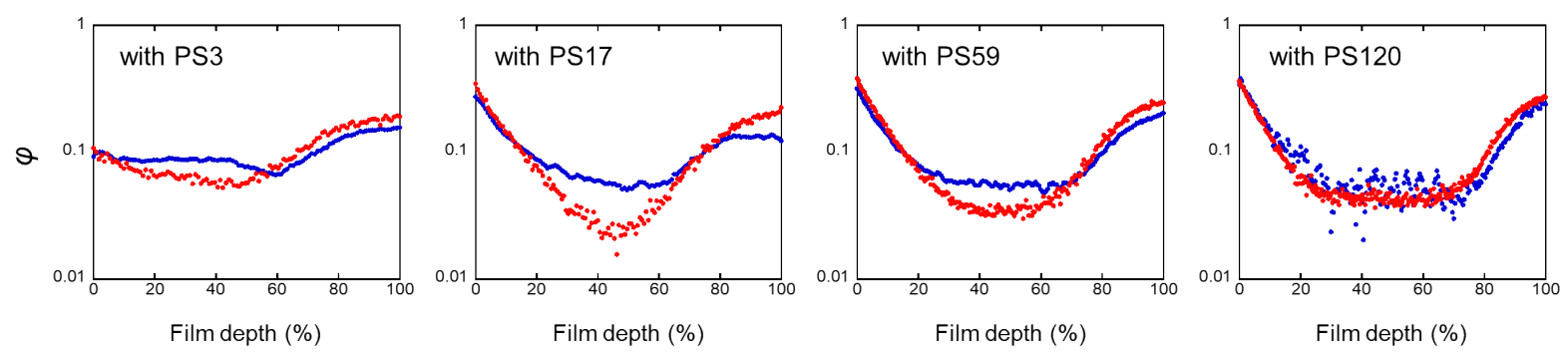

Figure S13. Mass fraction $\varphi$ of linear PCHMA as a function of film depth in linear PCHMA/PS as-cast (blue) and annealed (red) blend films. The polymer-air interface and substrate interface are at 0 and $100 \%$ film depth, respectively.

(a)

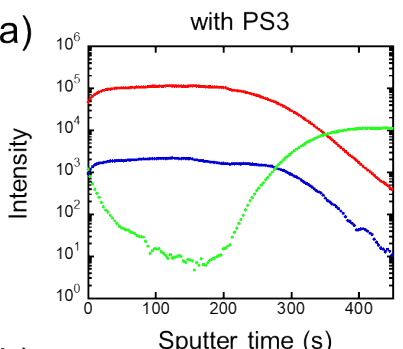

(b)

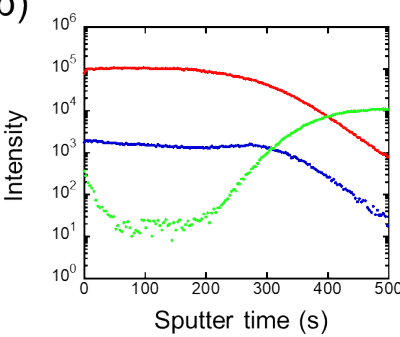

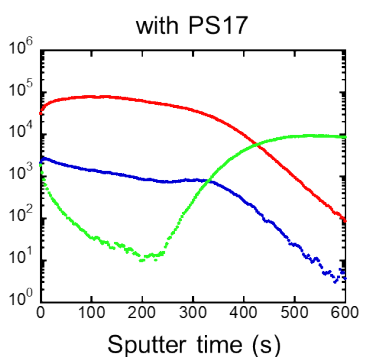

Sputter time (s)

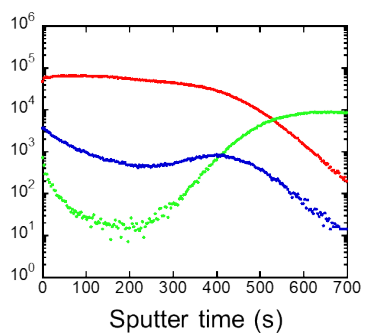

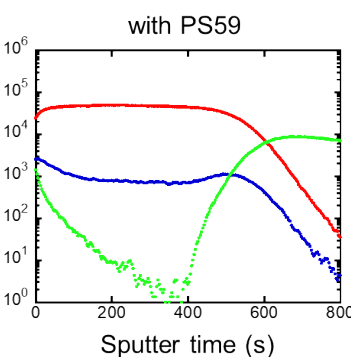

Sputter time (s)

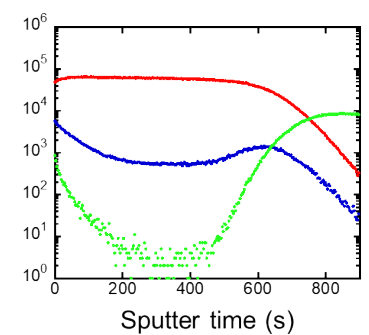

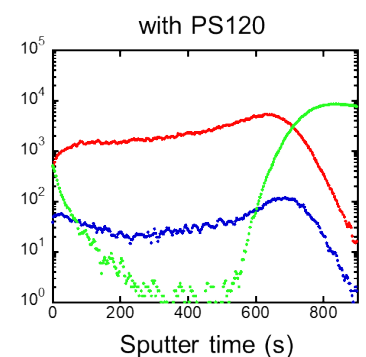

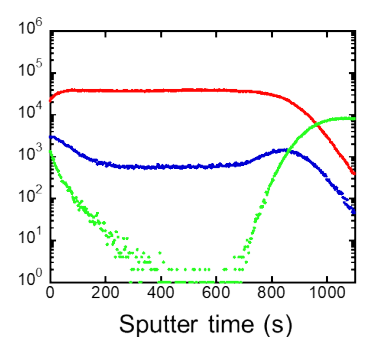

Figure S14. Uncalibrated secondary ion-intensities measured during ToF-SIMS depth profiling of (a) as-cast and (b) annealed linear PCHMA/PS blends. $\mathrm{C}_{6} \mathrm{H}_{11}{ }^{+}$(from PCHMA), $\mathrm{C}_{7} \mathrm{H}_{7}+$ (from PS), and $\mathrm{Si}^{+}$(from substrate) secondary ions are indicated in blue, red, and green, respectively.

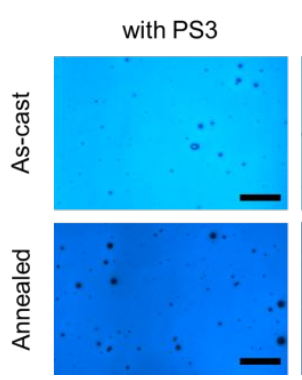

with PS17

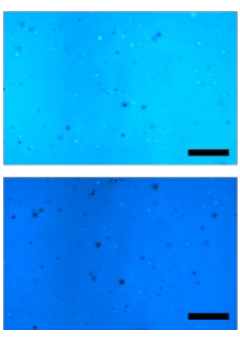

with PS59

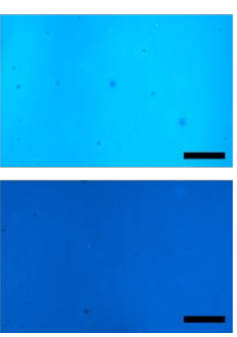

with PS120

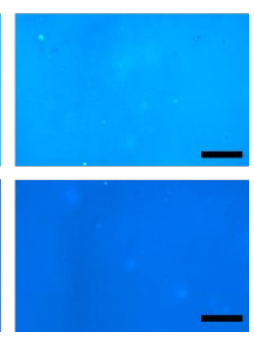


156 Figure S15. Optical micrographs of the series of linearPCHMA/PS blends as-cast and annealed at $150{ }^{\circ} \mathrm{C}$ for 2 days. Scale bar represents $50 \mu \mathrm{m}$.
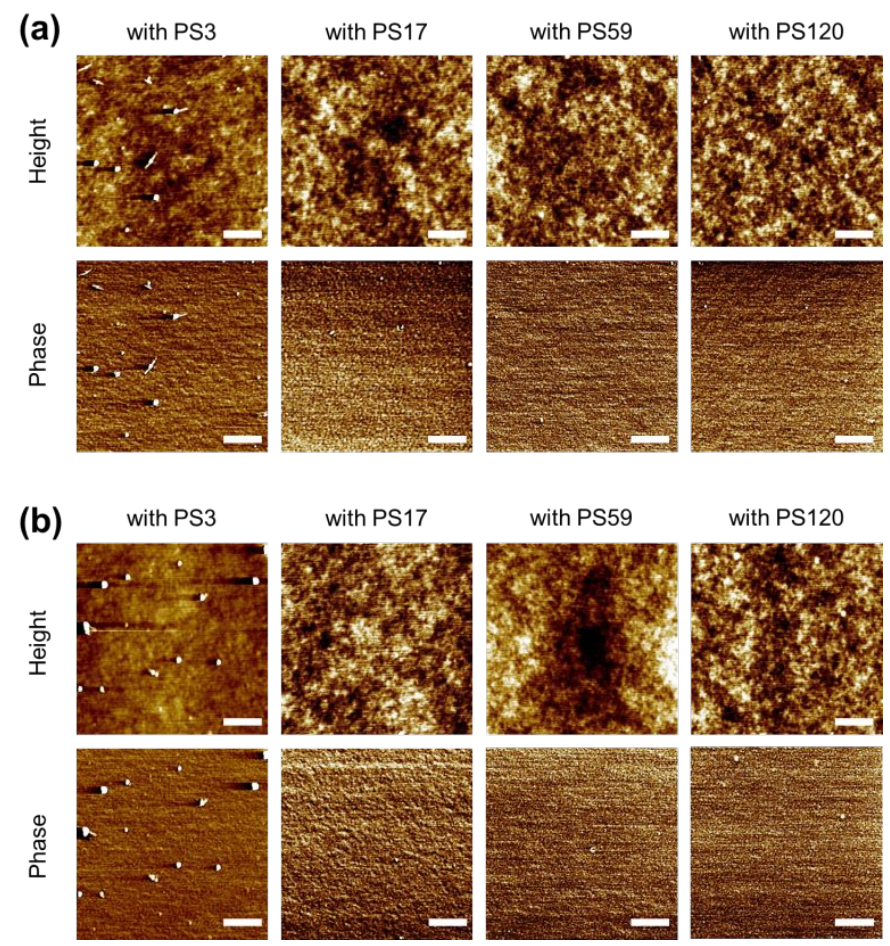

160 Figure S16. AFM height and phase images of the series of linear PCHMA/PS blends (a) as161 cast and (b) annealed at $150{ }^{\circ} \mathrm{C}$ for 2 days. Scale bar represents $1 \mu \mathrm{m}$. 


\section{Contact angle measurement and pendant drop method}

(a)

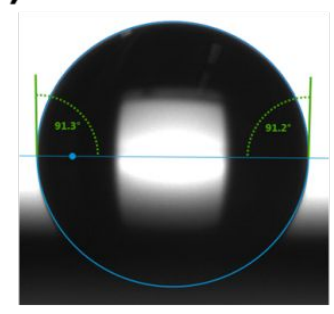

(c)

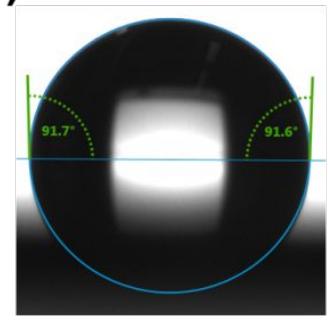

(e)

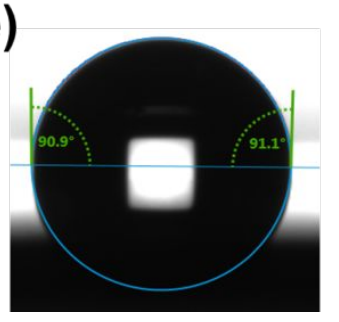

(b)

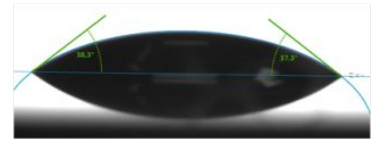

(d)

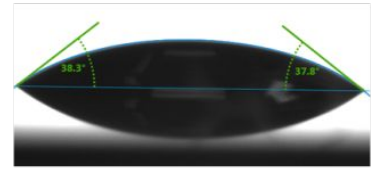

(f)

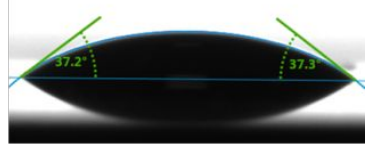

Figure S17. Contact angles of (a,c, and e) water and (b, d, and f) diiodomethane on the silicon wafer coated with BBPCHMA-25 (top), linear PCHMA (middle) and PS120 (bottom) at $25^{\circ} \mathrm{C}$.

(a)

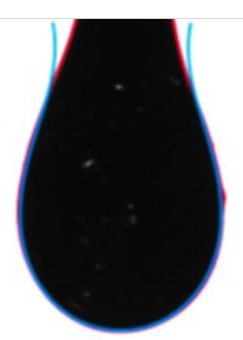

(b)

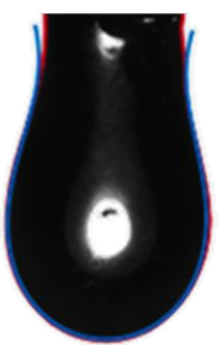

Figure S18. Pendant drop of melt (a) BBPCHMA-25 and (b) PS120 at $150{ }^{\circ} \mathrm{C}$. 
177 Table S3. Polar and disperse components of surface energy of BBPCHMA-25, linear PCHMA, 178 and PS120 at room temperature, obtained by OWRK method.

179

\begin{tabular}{ccc}
\hline Polymer & $\begin{array}{c}\text { Disperse } \\
(\mathrm{mN} / \mathrm{m})\end{array}$ & Polar $(\mathrm{mN} / \mathrm{m})$ \\
\hline BBPCHMA-25 & $40.70 \pm 0.08$ & $0.66 \pm 0.03$ \\
linear PCHMA & $40.99 \pm 0.14$ & $0.67 \pm 0.03$ \\
PS120 & $40.64 \pm 0.05$ & $0.65 \pm 0.03$ \\
\hline
\end{tabular}

180

181

182 


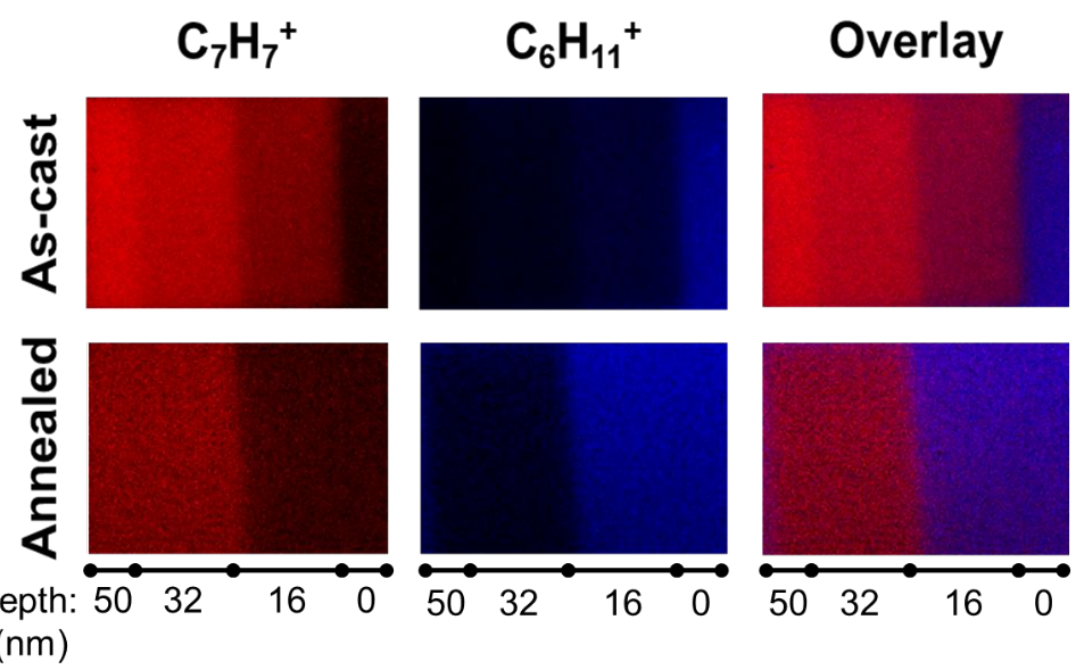

186 Figure S19. Two-dimensional, top-down analysis of "wedge crater" by ToF-SIMS before and 187 after annealing. The false color images show ion intensities corresponding to $\mathrm{PS}\left(\mathrm{C}_{7} \mathrm{H}_{7}^{+}\right)$and 188 BBPCHMA $\left(\mathrm{C}_{6} \mathrm{H}_{11}{ }^{+}\right)$and their overlay. The depth numbers reflect the depth of the wedge crater 189 over the regions indicated, for both annealed and as-cast films. The lateral dimension of the 190 region shown is approximately $300 \mu \mathrm{m}$. 